\title{
DA ORDEM DO DISCURSO AO DISCURSO DA ORDEM: DA RELAÇÃO ENTRE SABER E PODER EM FOUCAULT
}

FROM THE ORDER OF DISCOURSE TO THE DISCOURSE OF ORDER: THE RELATION BETWEEN KNOWLEDGE AND POWER IN FOUCAULT

Fernando Sepe Gimbo ${ }^{1}$

\section{RESUMO}

O artigo propõe uma reconstrução do problema da relação entre saber e poder tal como concebida por Foucault no início na década de 70. Para tanto, organizo minha exposição em torno de dois pontos principais: (1) mostrar a relação que Foucault estabelece entre discurso e ordem a partir das funções de exclusão relacionadas ao campo do saber; (2) recuperar a leitura consonante de Marcel Détienne e Nietzsche que subjaz a posição de Foucault, leitura através da qual ele distancia-se de certa concepção tradicional e clássica de verdade. $\mathrm{O}$ objetivo de tal reconstrução é expor de forma detalhada como a constituição da trama entre saber e poder esclarece e define o sentido do projeto foucaultiano de escrever uma história crítica do pensamento. Definição filosoficamente importante e fecunda, pois ela abre a perspectiva política que Foucault irá explorar durante todo o chamado período genealógico: a "história da verdade" será, doravante, escrita também como uma história política da verdade.

PALAVRAS-CHAVE: Foucault, verdade, saber, poder, discurso.

\section{ABSTRACT}

This article proposes a reconstruction of the problem of the relationship between knowledge and power as conceived by Foucault at the beginning of the 70 s. Therefore, I organize my argument around two main points: (1) show the relationship Foucault sets between speech and order recovering the functions of exclusion related to a system of knowledge; (2) recover Foucault's consonant read of Marcel Détienne and Nietzsche, reading through which he moves away of a traditional and classical conception of truth. The objective of this reconstruction is to expose in detail how the constitution of the relation between knowledge and power define the Foucauldian project of writing a critical history of thought. Definition philosophically important and fruitful, because it opens the political perspective that Foucault

\footnotetext{
${ }^{1}$ Professor do curso de Filosofia da UFCa; graduação em filosofia pela USP e mestrado pela UFSCar, com dissertação sobre o pensamento de Michel Foucault, pesquisa financiada pela FAPESP. E-mail: sepefernando@gmail.com.
} 
will explore in all his called genealogical period: the story of the truth must now be written as a political history of truth.

KEYWORDS: Foucault, truth, knowledge, power, discourse

\section{INTRODUÇÃO}

No início dos anos 70, Foucault expõe a passagem de seu eixo de pesquisa sobre o saber para o eixo do poder, enfatizando a ideia de que não devemos compreender sua genealogia como uma ruptura e, menos ainda, como uma oposição à arqueologia, afinal, a genealogia se apoiaria nos resultados da crítica arqueológica. A passagem da arqueologia à genealogia pode ser compreendida como uma ampliação do campo de investigação proposto por Foucault. Ampliação através da qual se desenvolve uma pesquisa mais precisa sobre a relação entre práticas discursivas $e$ não-discursivas, assim como sobre os seus efeitos na constituição da objetividade e da subjetividade. Com tal ampliação, o saber passa a ser analisado, também, em termos de estratégias e táticas de poder, situando-o no âmbito das lutas, em uma dimensão política, moral e social agonística.

Tendo tal passagem como pano de fundo, proponho neste artigo me centrar naquilo que acredito ser o primeiro ponto da sutura que Foucault costura entre saber-poder, a saber: a problematização do caráter de ordem presente em todo discurso. Para tanto, organizo minha argumentação em torno de dois pontos principais: (1) mostrar a relação que Foucault estabelece entre discurso e ordem a partir das funções de exclusão relacionadas ao campo do saber; (2) recuperar a leitura consonante de Marcel Détienne e Nietzsche que Foucault faz, leitura através da qual ele distancia-se de certa concepção tradicional e clássica de verdade.

O objetivo da reconstrução desse momento da experiência intelectual de Foucault é expor de forma detalhada como a constituição da trama entre saber e poder esclarece e define o sentido do projeto foucaultiano de escrever uma história crítica do pensamento (FOUCAULT, 2001b, p. 1451). Definição filosoficamente importante e fecunda, pois ela abre a perspectiva política que Foucault irá explorar durante toda a década de 70: a "história da verdade" será, doravante, escrita também como uma história politica da verdade.

\section{Da dupla acepção do genitivo}

Em sua aula inaugural no Collège de France - A ordem do discurso - Foucault propõe que o problema da veracidade de um discurso pode e deve ser investigado a partir de 
um duplo viés: (1) primeiramente, levando em consideração suas condições históricas de enunciabilidade e transformação; (2) em segundo lugar, investigando os procedimentos e práticas que produzem diversos efeitos na realidade a partir da partilha entre o verdadeiro e o falso. É sobretudo esse segundo eixo de pesquisa que estará em jogo a partir da década de 70.

Nesse sentido, proponho que o sintagma "ordem do discurso" deva ser entendido na acepção dupla do genitivo. Pois tal expressão indica, por um lado, que o discurso tem uma ordem própria, uma organização imanente, um sistema de regras através das quais seus elementos constitutivos se relacionam. Essa primeira acepção do termo determina o nível de investigação da arqueologia. Trata-se, aqui, da ordem própria e constitutiva do discurso, a “ordem das coisas" tal como descritas em seu livro de 66 - Le mots et le choses: "A ordem é ao mesmo tempo aquilo que se oferece nas coisas como sua lei interior, a rede secreta segundo a qual elas, de uma certa forma, se olham entre si e que só existe através do crivo de um olhar, de uma atenção, de uma linguagem” (FOUCAULT, 2007, p. XVI).

Mas, tal expressão designa também, inversamente, a ordem dada pelo discurso, a força e os efeitos práticos através dos quais um discurso se legitima e se efetiva dentro do corpo social. Eis o eixo de análise da genealogia. A partir da década de 70, trata-se tanto da ordem interna ao discurso, quanto da ordem externada pelo discurso: o discurso é uma palavra da ordem e de ordem.

O que esse eixo de análise revela é que o saber tanto efetiva uma ordem no campo social, quanto é produzido por essa mesma necessidade de organizar, disciplinar e controlar aquilo que pode ser dito e visto dentro de uma sociedade. Estamos rigorosamente no limiar, ou na passagem, entre dois momentos distintos da experiência intelectual foucaultiana. Isto quer dizer que as regularidades, deslocamentos e transformações que marcavam as descrições sistemáticas sobre o saber, na década de 60, têm como contraparte práticas e funções imanentes, porém não idênticas, às sistematicidades anteriormente descritas. Procedimentos relacionados às séries de enunciados que permitem, por exemplo, que determinada sociedade possa selecionar, induzir, derivar, ampliar, limitar, ou excluir, os "bons discursos" "dos maus". Não estamos mais, exclusivamente, no campo da condição de possibilidade de formação e transformação histórica de enunciados com pretensão à veracidade. Estamos no nível onde o valor desta pertença é produzido, tecido e decidido. Francis Wolff bem sintetiza o que se propõe: "É evidente que é neste nível que se joga a relação entre o poder que rege 
uma sociedade e os discursos que circulam, pois eles são levados à existência, ou condenados à inexistência, por exigências sociais exteriores" (F. WOLFF, 2006, p. 76). É precisamente nesse nível que podemos colocar a seguinte questão: qual inflexão o problema do poder opera em uma apreensão histórico-crítica do saber?

\section{As três funções de exclusão do discurso}

Foucault insiste durante toda a década de 70 que as relações de poder não deveriam ser descritas unicamente como repressivas, mas também como produtivas: elas tanto são uma relação de força de caráter prático, quanto uma perspectiva administrativa de seleção. Tal dinâmica biunívoca do poder é analisada em A ordem do discurso a partir de três funções de exclusão que cabe retomar. Elas evitam a conclusão fácil que entre poder e saber existiria apenas uma relação de sobredeterminação. Trata-se antes, como veremos, de determinações recíprocas:

\section{a) $A$ interdição (l"interdit)}

Com a interdição, Foucault destaca a dinâmica de controle própria àquilo que pode ser visto e dito: não podemos dizer e ver tudo ao mesmo tempo, ou em qualquer circunstância. "Tabu do objeto, ritual de circunstância, direito privilegiado ou exclusivo do sujeito que fala" (FOUCAULT, 1996, p. 11). O ver e o dizer encontram-se determinados por uma grade cerrada, em que a fala e a visão, o sujeito de enunciação e o objeto percebido, são determinados, alocados, redistribuídos. O espaço de circulação do saber é entremeado por dissimetrias de força e posição: não o espaço liso e ideal pressuposto pela comunicação, mas antes, o espaço estriado e real das relações de poder. Tais relações, no mesmo movimento que organizam e controlam o campo do discurso, também o produzem, determinando seus locais de aparição e enunciação. O conhecimento, como instância discursiva, produz-se na diástole entre dito e não-dito, entre a interdição e a licença da palavra. Tal dinâmica revela como o saber é indissociável de uma luta política constante, que há uma vontade, um desejo, que pulsa de forma muda na história do saber. O saber não é apenas dominação, como tantas vezes será levantado contra uma certa leitura vulgar de Foucault, pois a palavra "poder" não traz em si uma conotação exclusivamente negativa. Poder designa, apenas, que há em todo saber uma luta, um jogo de dominação e resistência, um campo dinâmico de forças que não 
se encontra de antemão subsumido pelos estratos do saber, pelo contrário, está em relação intrínseca com eles. Em outras palavras, o discurso torna-se o palco de um embate e não o espaço de uma conversação infinita que pressupõe o mútuo entendimento, a garantida vitória racional do melhor argumento. Antes, um campo construído sobre heterogeneidades, perspectivas divergentes, hierarquias e assimetrias de posições e forças, em última análise, irreconciliáveis. Há um pluralismo agonístico - um dissenso - na base da análise do discurso de Foucault. Daí esse desejo de apoderar-se do poder da palavra, de suspender as limitações embaralhando os locais de fala e as hierarquias simbólicas de autoridade, fazendo da verdade do discurso uma força de resistência. Dito de outro modo, o reconhecimento desse espaço estriado é indissociável de uma demanda ético-política por desconstrução dos imperativos de interdição, de pausa, segredo e silêncio - arbitrários e violentos - que as relações de saber e poder instituem e sancionam.

\section{b) A partilha (le partage)}

Esta segunda forma de exclusão é descrita por Foucault tendo como base seus estudos sobre a loucura. A grande ideia por detrás de tal função é mostrar como a razão não pode se efetivar historicamente sem delimitar territórios que se por um lado constituem um plano de consistência para o conhecimento e para a organização da vida social, por outro lado acabam sempre por lançar para o espaço da loucura, do mito, da patologia, do irracional, enfim, tudo

aquilo que não se coaduna com a normatividade própria às suas regras. Porém, como a arqueologia já nos mostrara, tais regras de partilha entre o dentro e o fora de uma cultura conhecem variações e transformações históricas que não podem ser plenamente fundadas nem em um ato originário da razão, nem em um telos que se efetivaria seguramente na marcha em direção à emancipação da humanidade. Tal recusa do universalismo e do historicismo teleológico abre uma perspectiva mais fecunda para uma história crítica da razão. Esta surge, agora, como uma série de sistemas que trazem em si uma divisão imanente, partilha que exige uma tarefa crítica de ampliação em direção a essa alteridade sempre lançada e condenada ao fora de uma época: "o que no fundo trata-se de examinar é uma razão cuja autonomia das estruturas traz consigo a história dos dogmatismos e dos despotismos - uma razão, consequentemente, que não tem efeito emancipador que a condição de se libertar de si-mesma" (FOUCAULT, 2001b, p.433). A função da partilha compreendida como exclusão coloca a questão ético-política de que a história da razão seja 
reescrita a contrapelo: história dos vencidos, dos silenciados, dos excluídos, dos asilados, dos apartados, dos marginalizados, com o risco de que, caso contrário, sobre a marcha triunfante da razão esclarecida, apenas multipliquemos e perpetuemos uma história de despotismo, dominação e violência, uma história crivada pelo preconceito e orgulho "dos vencedores". Consequentemente, as partilhas instituídas entre a razão e seu outro devem ser alvos constantes de uma crítica sempre recuperada.

\section{c)A oposição do verdadeiro/falso}

Primeiramente, Foucault começa por nos lembrar que ligar a oposição entre verdadeiro e falso - que parece em último caso nos remeter à lógica proposicional - à ideia de exclusão e, portanto, ao campo político-moral, parece um movimento bastante perigoso e equivocado. Afinal,

[...] como se poderia razoavelmente comparar a força da verdade com separações como aquelas, separações que, de saída, são arbitrárias, ou que, ao menos, se organizam em torno de contingência histórias; que não são apenas modificáveis, mas estão em perpétuo deslocamento; que são sustentadas por todo um sistema de instituições que as impõe e reconduzem; enfim, que não se exercem sem pressão, nem sem ao menos uma parte de violência? (FOUCAULT, 1996, p. 14-15)

Ou seja, Foucault sabe muito bem que caso nos coloquemos no nível formal da proposição e seu referente, a separação entre o verdadeiro e o falso diz respeito ao campo da lógica e, nesse sentido, ela não será "nem arbitrária, nem modificável, nem institucional, nem violenta" (FOUCAULT, 1996, p.14). Dito de outro modo, não há história da verdade do ponto de vista lógico-formal. Entretanto, Foucault explica que a arqueologia exigira outro campo de análise, campo histórico das transformações de enunciados circunscritos a determinada disciplina científica. Por isso, ela não se confunde com uma analítica formal da verdade. O objetivo de tal investigação - em sintonia com os trabalhos de história da ciência na tradição francesa - fora, precisamente, explicitar como determinadas partilhas entre verdadeiro/falso não se encontram de antemão e definitivamente fundadas, conhecendo transformações epistemológicas que podem ser recuperadas e conhecidas. Tal limitação às posições fundacionistas definitivas deixara entreaberto a possibilidade para uma outra investigação sobre a relação entre verdade e história. Uma história que coloque em primeiro plano o valor de verdade, isto é, a ideia de que a verdade é em si mesma um valor absoluto para o pensamento. É esta problematização genealógica que é desenvolvida a partir da 
segunda metade da conferência $A$ ordem do discurso. Sobre isso, segue uma longa citação que bem sintetiza o que estará, doravante, em jogo:

\begin{abstract}
Mas se nos situarmos em outro nível, se levantarmos a questão de saber qual foi, qual é constantemente, através de nosso discurso, essa vontade de verdade que atravessou tantos séculos de nossa história, ou qual é, em sua forma muito geral, o tipo de separação que rege nossa vontade de saber, então é talvez algo como um sistema de exclusão (sistema histórico, institucionalmente constrangedor) que vemos desenhar-se. Separação historicamente constituída, com certeza. Porque, ainda nos poetas gregos do século VI, o discurso verdadeiro - no sentido forte e valorizado do termo -, o discurso verdadeiro pelo qual se tinha respeito e terror, aquele ao qual era preciso submeter-se, porque ele reinava, era o discurso pronunciado por quem de direito e conforme o ritual requerido; era o discurso que pronunciava a justiça e atribuía a cada qual sua parte; era o discurso que, profetizando o futuro, não somente anunciava o que ia passar, mas contribuía para a sua realização, suscitava a adesão dos homens e se tramava assim como destino. Ora, eis que um século mais tarde, a verdade a mais elevada já não residia mais no que era o discurso, ou no que ele fazia, mas residia no que ele dizia: chegou um dia em que a verdade se deslocou do ato ritualizado, eficaz e justo, de enunciação, para o próprio enunciado: para seu sentido, sua forma, seu objeto, sua relação e sua referência. Entre Hesíodo e Platão uma certa divisão se estabeleceu, separando o discurso verdadeiro do falso; separação nova visto que, doravante, o discurso verdadeiro não é mais o discurso precioso e desejável, visto que não é mais o discurso ligado ao exercício do poder. O sofista é enxotado. (FOUCAULT, 1996, p. 14-15, grifo nosso).
\end{abstract}

Pela primeira vez na obra de Foucault surge a consciência de outro corte na história que marcará de forma profunda seu pensamento. Note-se que não se trata, como nos escritos da década de 60 , da transformação do fundamento do saber, por exemplo, a passagem entre uma era da representação para uma época centrada na figura do homem, como na descontinuidade entre episteme clássica e moderna. Essa outra partilha, que aqui se desenha, diz respeito ao caráter de poder que a verdade, como discurso, efetiva na relação entre os homens. Na esteira de Nietzsche e Détienne, Foucault irá sustentar uma tese que, a partir de então, parece atravessar a sua obra durante toda a década de 70: a tradição filosófica, ao postular uma disposição natural do pensamento à verdade e operar com uma concepção de linguagem entendida como representação, acabou por velar historicamente a dimensão de poder que se trama junto de todo saber discursivo.

A linguagem, com a tradição metafísica, torna-se algo capaz de dizer a verdade e não de fazê-la, ou produzi-la. Ela perde, então, seu caráter persuasivo e sua dimensão retórica essencial, para tornar-se "neutra" e capaz de espelhar plenamente o mundo. Mas, pergunta-se Foucault, o que se diz nesta transformação entre a função da verdade se não uma "vontade de 
saber", um compromisso moral com a partilha entre a prática de um discurso verdadeiro e outro falso? E junto com essa partilha, por conseguinte, não se define talvez um dos mais antigos sistemas de exclusão da cultura ocidental: expulsão dos poetas e sofistas, ou mais profundamente, o corte entre epistemê e doxa? Ora, insinua a genealogia: estamos no campo do saber, ou do poder? Trata-se de uma partilha absolutamente teórica, ou ela funda-se em uma valoração de um tipo de discurso sobre o outro? Mas, aqui, já não deslizamos para o campo moral?

\section{O discurso do mestre}

Foucault descreve tal descontinuidade a partir da diferença entre a "palavra do poeta grego do século VI A.C.” e o discurso filosófico iniciado com Platão e Aristóteles. Segundo Foucault, a verdade na Grécia arcaica era determinada por uma palavra que produzia um efeito real no corpo social: discurso poético que diz a justiça e profetisa o devir. Tal discurso tinha três características maiores ${ }^{2}$ : (1) ele não era independente daquele que falava, isto é, a verdade estava ligada a uma certa qualificação, ou autoridade, política e ética do sujeito de enunciação; (2) ele era inseparável de um ritual que o produzia e legitimava; (3) a palavra era carregada de força, de uma efetividade que nunca se separa de sua realização. Ou seja, la parole era uma ação.

Como dirá Foucault, entre Hesíodo e Platão há a diferença entre um discurso que compreende a verdade como acontecimento e um discurso em que a verdade é efetivada pela demonstração. Duas concepções diferentes que se justificam a partir da divergência no que diz respeito à natureza da linguagem e da relação do sujeito do conhecimento com o mundo. Nesse sentido, Foucault argumenta que quando a filosofia grega se estabelecer com Platão, a verdade deixa de estar ligada ao status de seu locutor para fundar-se na plena adequação ao conteúdo enunciado ${ }^{3}$. Dessa forma, o discurso passa a ser compreendido como objetivo ao seguir regras racionais que garantem a perfeita adequação entre as palavras e as coisas. Platão afirmará no Crátilo (358b) que a verdade é “dizer as coisas como elas são" e o logos

\footnotetext{
${ }^{2}$ Além do texto de Detienne, sigo aqui alguns apontamentos de leitura do texto de B. HAN (2000): Nietzsche and the "Master of truth".

${ }^{3}$ Note-se a tensão entre esta perspectiva que atravessa o ensinamento de Foucault na década de 70 no Collège de France e aquela desenvolvida já na década de 80 quando os conceitos de parresia e cuidado de si tornarem-se essencial para a leitura que Foucault propõe da filosofia grega, inclusive dos textos socráticos e platônicos. A esse respeito ver, sobretudo, A hermenêutica do sujeito, O governo de si e dos outros e A coragem de verdade.
} 
apofântico de Aristóteles se torna possível: "dizer do ser que ele é e do não ser que ele não é, é dizer o verdadeiro" (ARISTÓTELES, Metafísica $\Gamma, 1011 \mathrm{~b} 25)$.

A transformação, em outras palavras, diz respeito à passagem entre um regime de verdade em que o discurso verdadeiro se diz de forma performativa - a verdade é indissociável da palavra que a realiza - para um regime de verdade em que o discurso se torna constatativo: "chegou o dia em que a verdade se deslocou do ato ritualizado, justo, eficaz, de enunciação, para o enunciado em si-mesmo: para seu sentido, sua forma, seu objeto, sua relação ao referente." (FOUCAULT, 1996, p.15) Em suma, com o surgimento da filosofia e do discurso sobre o ente, a linguagem deixa de ser considerada como um elemento indispensável na produção da verdade que é dita, para tornar-se, simplesmente, a enunciadora de uma verdade plena em-si. Veracidade do discurso fundada em regras que constituem um método preciso e disponível a todo sujeito humano, pois constitutivo de sua natureza racional. Dupla transformação portanto: tanto na concepção da ideia de verdade, quanto na sua forma de aquisição e justificação.

Tais transformações indicadas por Foucault baseiam-se nos estudos históricos de Vernant e, sobretudo, no clássico livro de 1967 de Marcel Détienne - Les maîtres de verité dans la Grèce archä̈que. Neste livro, Détienne expõe exatamente esta diferença interna à história da cultura ocidental tal como retomada por Foucault. Para o historiador francês, a questão é saber “como se deu esta passagem (...) para um novo regime intelectual, este da argumentação e do princípio de contradição, junto da transição para o diálogo e a referência da proposição.” (DÉTIENNE, 2006, p.9) Em outras palavras, trata-se de pensar a gênese da concepção adequacionista de verdade, concepção indissociável "das noções de verificação e demonstração" (DÉTIENNE, 2006 p.51) Para tanto, Détienne recupera o pensamento arcaico estabelecendo uma rigorosa comparação com o discurso metafísico, comparação através do qual a diferença pode ser bem delimitada: "Na Grécia arcaica, os mestres de verdade têm o privilégio de dizer a verdade simplesmente por estarem envoltos em qualidades que os tornam especiais”. (DÉTIENNE, 2006 p.8) Isto é, a verdade é inseparável do sujeito que a enuncia, de sua função e reconhecimento social, do poder de sua palavra: "Quando o poeta engrandece alguém, ou algo, ele o faz em seu próprio nome, a partir da aletheia: sua palavra é alethes, como sua mente. O poeta é um mestre da verdade" (DÉTIENNE, 2006, p. 68).

A verdade (aletheia), neste caso, tem como condição a alethes (honestidade, veracidade, confiança pública) daquele que fala. Consequentemente, Détienne insiste que para 
o pensamento arcaico a verdade de um discurso não é de natureza plenamente objetiva. Pelo contrário, ela depende da habilidade pessoal do orador de falar de forma convincente e autêntica. Um "mestre da verdade" é, antes de tudo, um artífice da palavra capaz de "instituir por sua virtude própria um mundo simbólico-religioso que é o próprio real” (DÉTIENNE, 2006, p. 67).

É assim, por exemplo, que Vernant nos lembra como a memória na Grécia arcaica não é psicologicamente orientada, isto é, ela não visa reconstruir algum evento passado segundo uma perspectiva narrativa temporal (VERNANT, 1965). A memória, pelo contrário, diz respeito a um privilégio de certos grupos, ou confrarias, e nisso sua função é dupla: “celebrar os imortais, celebrar os grandes feitos dos homens valentes" (DÉTIENNE, 2006, p. 68). Não se trata, contudo, de que os poemas em memória de um rei, ou herói de guerra, diga respeito a fatos históricos averiguados. A poesia é um discurso mântico que enuncia o passado e anuncia o futuro, mito que atravessa as gerações, discurso que fala daquilo "que foi, que é e que será" (DÉTIENNE, 2006, p. 66).

De forma homóloga, o discurso do tirano, ou do juiz, tem caráter oracular. Discurso completamente estranho a nossa sensibilidade educada pelo direito moderno, um rei que faz justiça, explica Détienne, não o faz porque sua sentença encontra-se plenamente adequada à realidade dos fatos, ele não realiza necessariamente uma investigação em busca da reconstituição de um evento. Pelo contrário, sua sentença transforma o "fato", por exemplo, absolvendo o acusado da culpa, ou ainda, condenando-o de forma perpétua: a palavra "realiza a justiça; ela instara a ordem do direito sem prova nem investigação" (DÉTIENNE, 2006, p. 8).

Logo, a aletheia arcaica é um modo complexo e característico do dizer-verdadeiro na Grécia pré-platônica. Palavra de poder que surge entre as juras de maldição e os cantos de bendição, entre a ordem de execução e as súplicas de perdão, tramada entre a vidência dos poetas e o confronto trágico das guerras, a aletheia é um acontecimento inseparável do poder: "Aletheia designa uma verdade assertórica: trata-se de um poder eficiente, ela cria o ser" (DÉTIENNE, 2006, p. 9). Détienne sublinha que essa potência própria à verdade deriva não apenas da função social daquele que detém a palavra (poeta, profeta, juiz, rei), mas também de suas qualificações éticas, de seu caráter, ou "nobreza de espírito". Isto é, ela revela que para a Grécia pré-platônica a linguagem é indissociável do poder que aquele que fala exerce sobre outros. Pois, uma vez que a linguagem seja entendida como um sistema simbólico 
neutro - sobretudo a partir da invenção da escrita - ela torna-se indissociável de uma imagem homogênea, de um caráter atônico e independente das relações de ascendência entre indivíduos. A verdade dita pela linguagem, todavia, não é apenas adequação. Como explica Bento Prado Júnior (2008, p.131-145), algo da palavra sempre escapa, desdobrando-se de forma heterogênea, matizada por intensidades diferentes, por tons e ênfases que transmitem algo para além do simples enunciado. Para a Grécia arcaica, a força da linguagem reside e se revela não apenas em seu caráter sintático, mas também e sobretudo, na subordinação de grau à diferença de qualidade intensiva, da clareza demonstrativa à qualidade moral. É exatamente esta tensão que está em jogo na passagem entre discurso arcaico e discurso filosófico.

Tal transformação recuperada por Foucault na esteira de Détienne pode ser entendida como uma primeira imagem a orientar nossa compreensão de sua genealogia, tal como o corte entre uma era da representação e uma era do homem marcara de forma constitutiva todas as obras da década de 60. De certa forma, podemos apreender a complementariedade entre arqueologia e genealogia através destas duas imagens, uma vez que a segunda se atém às regras, à ordem de um discurso; já a primeira se desenha a partir desta dimensão prática do discurso, desta expressão do caráter de força e persuasão que institui suas funções sociais, ou seja, seus efeitos reais: a exclusão, as partilhas, o estabelecimento da autoridade do verdadeiro, etc. Questão fundamental para Foucault, se a regras são condições necessárias para todo discurso, elas não são condições suficientes no que diz respeito à produção de efeitos no corpo social. É precisamente aqui, insisto, que tanto Détienne quanto Nietzsche se tornam essenciais para Foucault.

\section{Verdade e mentira}

Em 1969 aparece em francês a primeira tradução do texto de juventude de Nietzsche intitulado Üeber Wahrheit und Luege im aussermoralischen Sinne, tradução feita por Angèle Kremer-Marietti, uma filósofa próxima a Foucault. Como nos lembra Daniel Defert em seu comentário sobre o curso de $70-71^{4}$ - primeiro curso de Foucault no Collège de France, curso dedicado aos gregos a partir de uma leitura consonante entre Détienne e Nietzsche este texto é uma das peças fundamentais para a interpretação foucaultiana da filosofia de

\footnotetext{
${ }^{4}$ Defert, Daniel, Situations du cours, p.266, in. Leçons sur la volonté de savoir, (2011)
} 
Nietzsche ${ }^{5}$. Por isso, seguindo tal pista, proponho aqui uma recuperação parcial das ideias centrais do texto de juventude de Nietzsche como uma tentativa de lançar certa luz à posição foucaultiana no que diz respeito ao problema da relação entre discurso e poder.

A primeira vista, Sobre verdade e mentira parece ter como alvo a ideia de verdade como adequação, mostrando a incapacidade da linguagem falar diretamente das coisas mesmas devido ao seu caráter metafórico: “Acreditamos saber algo das coisas mesmas, se falamos de árvores, cores, neve e flores, e, no entanto, não possuímos nada mais do que metáforas das coisas, que de modo nenhum correspondem às entidades de origem" (NIETZSCHE, 1974, p. 55-56). Contudo, é notável como Nietzsche constrói seu texto a partir de um astucioso deslizamento. Pois, a ideia de que a linguagem seja um sistema arbitrário de signos utilizado para referir-se ao mundo, em nenhum momento aparece como a principal tese a ser provada. O filólogo alemão a toma, de certo modo, como uma antecâmara para o problema central, a saber, a questão referente ao Trieb zur Wahrheit: "Continuamos ainda sem saber de onde provém o impulso à verdade: pois até agora só ouvimos falar de obrigações que a sociedade, para existir, estabelece: de dizer a verdade, isto é, de usar as metáforas usuais, portanto, expresso moralmente” (NIETZSCHE, 1974, p. 54). A questão desloca-se: podemos facilmente compreender que a linguagem tenha uma constituição convencional, em última análise, condição para toda e qualquer comunicação intersubjetiva que esteja na base da organização social. Mas, nesse caso, apenas substituímos uma noção de adequação por uma compreensão pragmática de verdade. A pergunta do filólogo Nietzsche, entretanto, é outra: o que se diz nessa obrigação de dizer a verdade que a sociedade, para existir, estabelece?

Como alguns comentadores já apontaram ", as anotações de 1872 intituladas "Curso de retórica" nos dão indicações bastante precisas para a compreensão desse problema. Aparentemente, a cultura filológica de Nietzsche exige uma reabilitação da retórica contra a ideia da possibilidade de uma linguagem neutra e perfeitamente adequada para o conhecimento das coisas. O ponto de partida é a definição aristotélica: “Admitamos, pois, que a retórica é a força de considerar teoricamente o que, em cada caso, é o mais conveniente

\footnotetext{
5 Por exemplo, em sua série de palestras na PUC do Rio de Janeiro em 1974 (FOUCAULT, 2001a, p.1406-1514), ou na Conferência dada na universidade de McGil em abril de 1971 e editada junto com o curso de 1970- 71.

${ }^{6}$ Por exemplo, Thelma Lessa da Fonseca - Nietzsche: Crítica à linguagem como crítica à moral, in. Revista Discurso (25), 1995, p.97-119; Philippe Lacoue-Labarte. Le detour, in. Poétiques, $n^{o}$ 5, Paris, 1975. Sigo aqui, ponto a ponto, o comentário de LESSA da FONSECA (1995) de onde retiro as traduções do curso de Nietzsche.
} 
para persuadir" (ARISTÓTELES, Retórica, I.2, 1355b). Como sabemos, na antiguidade, a retórica é definida como uma tekhné que consiste na habilidade do uso da linguagem em direção à persuasão do ouvinte.

Nietzsche, contudo, dá um passo a mais. Ele defende que o caráter metafórico da linguagem, assim como sua força retórica, talvez não seja sempre um artifício utilizado de forma consciente e intencional, como no caso do poeta e do sofista, mas antes, trata-se de uma dimensão inconsciente e esquecida da própria “origem" da linguagem:

[...] não é difícil provar que isto que a que chamamos "retórica" para designar os meios de uma arte consciente já estava em ação, como os meios de uma arte inconsciente na linguagem e na formação desta [...] não é difícil provar que a retórica é um aperfeiçoamento dos artifícios já presentes na linguagem. (NIETZSCHE, 1922, p. 297-98, apud. LESSA da FONSECA).

Tal origem retórica é defendida por Nietzsche a partir da seguinte questão: qual a gênese de uma palavra? Para o filólogo alemão, a palavra é um tropo no sentido que ela assinala apenas a característica que aquele que nomeia julga relevante, isto é, na palavra recorre-se a uma imagem que seleciona e enfatiza um aspecto em detrimento de outro. Três são as figuras de linguagem utilizadas por Nietzsche para defender tal ponto: sinédoque, metáfora e metonímia. Por exemplo, a palavra "serpente" - serpens: aquilo que se arrasta - é escolhida para designar um animal. Mas, "por que serpens não significa também caracol?" (NIETZSCHE, 1922, p.229, apud. LESSA da FONSECA). Nesse caso, temos uma sinédoque em que tomamos a parte pelo todo a partir da seleção de uma característica daquilo que é nomeado. O mesmo com drákon - "aquele de olhar brilhante" - que designa o mesmo animal em grego. Já na metáfora, Nietzsche sublinha a dinâmica de transposição inerente a toda linguagem, por exemplo, quando utilizamos palavras como "pé", "veia”, ou "cabeça", para se referir às partes de uma montanha. Por fim, a metonímia é entendida como uma operação de substituição entre causa e efeito, por exemplo, quando o retórico diz "suor" ao invés de "trabalho" (LESSA da FONSECA, 1995, p.105).

A partir de uma densa análise desses três tipos de figuras de linguagem - que aqui apenas apontamos brevemente - Nietzsche sugere que podemos pensar que os tropos não são apenas exceções, ou anomalias criadas de forma artificial pela retórica. Pelo contrário, eles revelariam uma dinâmica própria à emergência das palavras, o modo de constituição próprio da linguagem. Tudo se passa como se nestas figuras retóricas fosse possível auscultar uma 
origem esquecida, pelo uso cotidiano, da linguagem como uma prática social. O tropo marcaria, por conseguinte, a invenção da palavra e, consequentemente, a retórica faria parte da gênese histórica de toda e qualquer língua: “da mesma forma que há tão pouca diferença entre as próprias palavras e os tropos, há a mesma diferença - mínima - entre o discurso autêntico e as chamadas figuras retóricas" (NIETZSCHE, 1922, p.229 apud. LESSA da FONSECA).

Mas, apenas dizer isso seria pouco. Pois é preciso, também, mostrar como a finalidade própria às palavras também pode ser retórica, não apenas sua gênese. Ora, pergunta-se Nietzsche, sobre o que falamos, ou o que queremos transmitir, quando usamos um tropo para designar uma impressão sensível? É claro que não se trata de que a palavra possa recuperar plenamente um estímulo, visto sua arbitrariedade e caráter figurativo. A palavra deve ser compreendida, pelo contrário, como evocativa, pois ela busca evocar - no outro - um estímulo, uma sensação, uma experiência, e não transmitir uma representação interna à mente do sujeito. Para Nietzsche, não há homologia entre estados mentais e palavras. Mas, se é assim, essa pretensão no uso da linguagem parece aproximá-la muito mais da retórica - em que a persuasão (peithein) é entendida como a tentativa de suscitar no outro paixões e afetos do que da linguagem como instrução, como órganon originário de transmissão do conhecimento.

Em suma, como mostrou Lessa da Fonseca (1999, p.110), estas duas ideias - as palavras têm em sua origem um tropo e a linguagem visa à evocação de um estímulo, ou emoção - sustentam a posição de Nietzsche de que a antiguidade clássica cometeu um estranho engano ao recusar o caráter retórico da linguagem o qualificando como um artifício secundário, em contraposição a um uso supostamente autêntico e natural, isto é, uso que estaria fundado em uma relação originária do conhecimento humano com a coisa significada.

É preciso aqui, nos parece, ter o cuidado de não tomar tal argumentação como se Nietzsche propusesse outra definição da “essência da linguagem". Talvez, seja mais interessante inscrever tal questão dentro de um quadro polêmico - caro a toda genealogia em que o preconceito moral da transparência entre verdade e linguagem é tensionado com a recuperação de seu caráter retórico. Nesse caso, a linguagem tona-se um estranho quiasma entre doxa e epistemê. Pois, que em sua "origem" a linguagem transmita uma opinião breve e não um conhecimento absolutamente fundado, não impossibilita que, posteriormente, ela possa transmitir um conhecimento entendido como verdade convencional. Pelo contrário, o 
que tal posição propõe é que ainda que a linguagem transmita algum tipo de conhecimento, isto não é garantia de que no discurso aceito como verdadeiro não haja nenhum elemento de persuasão e coerção. Consequentemente, a gênese da valoração irrestrita de uma linguagem transparente ao conhecimento puro pode e deve ser posta em suspeita.

Dito isso, podemos agora voltar à questão de partida sobre a origem do impulso à verdade. Pois, se não há uma linguagem puramente neutra e engendrada a partir da confrontação do sujeito com as coisas mesmas, como fora possível o surgimento de um discurso que crê dizer das coisas o que elas são em-si mesmas? Qual a proveniência dessa expectativa de fixidez, dessa vontade ilimitada de uma verdade sempre reencontrada pela linguagem? Ela apenas pôde surgir, enfatiza Nietzsche em Verdade e mentira, a partir da interpretação da verdade como um valor em si-mesmo necessário, desejável e válido. É a interpretação do mundo como mundo verdadeiro que faz com que o uso "legítimo" da linguagem seja o uso veraz e não o contrário. Com tal descarte da ideia metafísica de causa final, o uso da linguagem torna-se indissociável de uma valoração moral prévia, de uma perspectiva de avaliação.

O notável, seguindo a leitura de Lessa da Fonseca, é perceber como a precedência genealógica da retórica quanto à ideia de um uso reto e seguro da língua propicia uma inversão do senso comum filosófico: agora é a própria ideia de um uso natural da linguagem que surge como uma retórica, como uma "astúcia que visa à persuasão" (1995, p.112). A dicotomia entre uma linguagem do conhecimento - constituída segundo a natureza humana e uma linguagem sofística - artifício daquele que visa persuadir alguém sobre algo que ele não sabe - é interpretada como uma partilha histórica daquilo que não estava separado originariamente.

Mas, o que revela tal "partilha" se não, precisamente, as relações entre nosso impulso à verdade e exigências morais, essas obrigações que a sociedade, para existir, estabelece? Caso aceitemos tal problematização nietzschiana, como Foucault o faz, a questão do conhecimento desliza necessariamente para o campo moral, pois, doravante, o pendor à verdade é indissociável de uma perspectiva que impõe a veracidade como valor absoluto: " $a$ veracidade e a metáfora produziu a propensão para a verdade. Assim um fenômeno moral, esteticamente generalizado, dá o impulso intelectual” (NIETZSCHE, apud. LESSA DA FONSECA, p. 111, 1995). 
Daí que a partilha entre filosofia e sofística diga respeito não apenas a bipolaridade verdadeiro/falso. O sofista é enxotado porque ele representa uma forma de vida que é um perigo a suposta organicidade da polis. Como nota Lessa da Fonseca (1995, p.115), a sofística se opõe a verdade não com o erro, mas com a mentira: “A verdade grega, outrora, tremeu nesta simples afirmação: „Eu minto "”, (FOUCAULT, 2001a, p. 546). Ora, nesse caso, como poderemos tranquilamente falar de acordo comum, consenso e convenção, uma vez que toda partilha é, também, uma coerção, um ritual social de seleção, persuasão e exclusão?

\section{Esquecimento e genealogia}

É notável como os estudos históricos de Détienne das estruturas do dizer-verdadeiro da Grécia pré-platônica estejam em profunda ressonância com a problematização moral da verdade tal como proposta por Nietzsche ${ }^{7}$. Parece-me que é neste encontro entre Détienne e Nietzsche que Foucault costura uma leitura e recuperação do pensamento clássico feita a contrapelo das interpretações filosóficas vigentes em sua época ${ }^{8}$.

Abordar a Grécia de um ponto de vista histórico-filológico, em detrimento de uma leitura hermenêutica, é a primeira opção decisiva de Foucault. Opção que o separa da posição majoritária de sua época, como nos explica Daniel Defert: “Em 1970, abordar filosoficamente a Grécia a partir de Nietzsche não é mais evidente. O helenismo filosófico não é mais nem hegeliano, nem nietzschiano, mas na França, ao menos, ele é segundo Heidegger" (DEFERT, 2011, p. 272). Seria enganoso, todavia, crer que tal opção de Foucault se justifica por mera afinidade metodológica. Pois, o que está em jogo, na verdade, é uma apropriação bastante singular e criativa da filosofia de Nietzsche em oposição a algumas teses filosóficas importantes à época.

Em seus comentários sobre o pensamento de Nietzsche, Foucault nunca se refere à posição de Heidegger. Ainda assim, podemos perceber como ele apresenta sua leitura em franca oposição à interpretação heideggeriana. A diferença se expressa já no pressuposto de cada leitura. Em nenhum momento Foucault adentra o pensamento de Nietzsche a partir da problemática da Wille zur Macht, pelo contrário a questão que ele privilegia é o da vontade de

\footnotetext{
${ }^{7}$ A esse respeito, ver o já citado estudo de HAN (2000).

${ }^{8}$ A esse respeito, cabe lembrar como na década de 70 a leitura heideggeriana de Nietzsche já era bem estabelecida na França, assim como suas engenhosas interpretações da filosofia grega.
} 
verdade: "eu lia Nietzsche e comecei a perceber o que me fascinava. Uma morfologia da vontade de verdade dentro da civilização europeia, que nós deixamos de lado em favor de uma análise da vontade de poder" (FOUCAULT, apud. DEFERT, 2011, p. 262). Disso se segue que Foucault concentre-se, sobretudo, em textos como Verdade e Mentira, Aurora e A gaia ciência, além, claro, da Genealogia da moral. Mas, mais do que isso, que ele tenha uma sensibilidade ampliada em direção ao problema da linguagem e da descontinuidade com a tradição metafísica que a crítica do conhecimento em Nietzsche exige para si.

É assim que Foucault começa seu curso sobre a vontade de saber ${ }^{9}$ (70/71) opondo, exatamente, Nietzsche a Aristóteles. Tal oposição baseia-se na descontinuidade entre dois paradigmas distintos de compreensão do conhecimento. Segundo Foucault, em Aristóteles encontramos uma inscrição do desejo de conhecimento dentro da natureza humana, como nos lembra a primeira frase de sua Metafísica: "todos os homens têm, por natureza, desejo de conhecer" (ARISTÓTELES, Metafísica, 1 980a). A superioridade da vida contemplativa deriva exatamente desse impulso natural à verdade e do direito próprio ao pensamento de obtê-la e possuí-la.

Por isso, a filosofia não cansará de postular uma harmonia entre intelecto e mundo, entre a linguagem e as coisas, entre a ordem das razões e a ordem da natureza. Estabelecendo assim uma abertura originária em que repousam enlaçadas razão e verdade a partir de um postulado surpreendentemente não criticado, a filosofia como discurso metafísico - desde sua origem - evita que a verdade se refira a elementos não-racionais, como a uma vontade, ao desejo e às paixões. Mais do que isso, a filosofia evita que a sua verdade se refira a um campo determinado de forças e instintos, depurando supostamente a verdade filosófica de qualquer elemento contingente e particular, liberando-a como uma sagesse universal e essencialmente inscrita na determinação da razão humana. Dessa forma, define-se de antemão que o pensamento tem como elemento o verdadeiro. A ilusão, ou o erro, apenas serão descaminhos e confusões inerentes a uma razão desprovida de método, ou de uma confusão incapaz de assegurar os limites precisos para cada faculdade de conhecer. Disso se segue, por exemplo, o tema clássico das potências ilusórias do corpo e da imaginação.

O objetivo de Foucault parece ser contrapor-se a essa imagem clássica do pensamento que funcionaria como fundo falso para uma reflexão filosófica que se crê livre de

\footnotetext{
${ }^{9}$ Foucault traduz Trieb zur Wahrheit, em geral, como "volonté de savoir", claramente trazendo tal expressão de Nietzsche para junto de seu léxico.
} 
pressupostos. Imagem naturalizada pela tradição e que pode ser resumida em três teses principais, como o faz Deleuze:

\begin{abstract}
A imagem dogmática do pensamento aparece em três teses essenciais: $1^{\circ}$ dizemos que o pensador enquanto pensador quer e ama o verdadeiro (veracidade do pensador); o pensamento como pensamento possui e contêm formalmente o verdadeiro (inatismo da ideia, a priori dos conceitos); pensar é o exercício natural de uma faculdade, logo, é suficiente pensar "verdadeiramente" para pensar com verdade (direito natural do pensamento, bom senso universalmente partilhado); $2^{\circ}$ Nos dizem, também, que somos afastados do verdadeiro, mas por forças estranhas ao pensamento (corpo, paixões, interesse sensível); Porque nós não somos apenas seres pensantes, nós caímos no erro, tomando o falso pelo verdadeiro. $\mathrm{O}$ erro: este seria o único efeito, no pensamento como tal, das forças exteriores que se opõe ao pensamento; $3^{\circ}$ Nos dizem, enfim, que é suficiente um método para bem pensar, para verdadeiramente pensar. O método é um artífice, mas pelo qual nós nos juntamos à natureza do pensamento, nós aderimos a esta natureza e conjuramos os efeitos das forças exteriores que nos alteram e distraem. Pelo método, nós conjuramos o erro. Pouco importa a hora e o lugar, se nós aplicamos o método: ele nos faz penetrar no domínio do que vale "em todos os tempos, em todos os lugares." (DELEUZE, 2010 p.118)
\end{abstract}

Foucault contrapõe tal imagem à cisão nietzschiana em que o conhecimento não é entendido como algo puro, natural e imanente ao espírito humano, mas sim, como uma invenção material e histórica (Erfindung):

Em algum remoto rincão do universo cintilante que se derrama em um sem número de sistemas solares, havia uma vez um astro, em que animais inteligentes inventaram o conhecimento. Foi o minuto mais soberbo e mais mentiroso da "história universal": mas também foi somente um minuto. Passados poucos fôlegos da natureza congelou-se o astro, e os animais inteligentes tiveram de morrer. (...) Pois não há para aquele intelecto humano missão mais vasta, que conduzisse além da vida humana. Ao contrário, ele é humano, e somente seu possuidor e genitor o toma tão pateticamente, como se os gonzos do mundo girassem sobre ele. (NIETZSCHE, 1974, p. 55, grifo nosso).

Como nota Foucault (FOUCAULT, 2001a, p1004-1024.), o termo Erfindung é retomado por Nietzsche em diversas ocasiões e textos. Ele se opõe à ideia de origem, mas não a origem como começo, mas sim como Ursprung, como esse liame originário entre o ser-do- homem, a verdade e o mundo. A contraposição ao tema metafísico da origem corresponde à negação de que o conhecimento seja o impulso, ou desejo, mais essencial do homem e, sobretudo, "que a possibilidade do conhecimento não é definida pela forma do homem, (...) sua possibilidade não é uma lei formal" aplicada pelo sujeito do conhecimento à realidade (FOUCAULT, 2011 p.196). Pelo contrário, o saber encontra sua possibilidade 
em um espaço complexo em que uma série de elementos, muitos não-racionais, têm papel decisivo de constituição:

Para Nietzsche, a relação entre vontade e verdade é completamente outra. A verdade está somente dentro dos elementos da vontade a partir de seus caracteres singulares e de suas mais precisas determinações, sob a forma da restrição e da dominação. A articulação de uma sobre a outra não é a da liberdade, mas sim o da violência. Essa mudança tem um efeito considerável que nós estamos longe de podermos compreender [...] ela deveria tornar impossível toda uma ideologia do saber como efeito da liberdade e recompensa da virtude. (FOUCAULT, 2011, p. 207).

O que Nietzsche faz, destaca Foucault, é propor uma interpretação sobre o saber que rompe com qualquer homologia entre conhecimento humano e mundo. Consequentemente, a verdade torna-se indissociável e confunde-se com a sua gênese humana e histórica. $\mathrm{O}$ conhecimento "não precede a si mesmo, ele é sem secreta antecipação" (FOUCAULT, 2011, p.197). Em uma "história da verdade" baseada em Nietzsche, explica Foucault, o saber não é o reflexo reencontrado das coisas pelo discurso, antes, ele revela "que o conhecimento é o resultado de uma operação complexa” e, por isso, é preciso refazer a história dessas operações, buscar a gênese de nossa irrestrita valoração da verdade (FOUCAULT, 2011, p.198).

Para a genealogia o saber é indissociável da história das técnicas, das imposições de partilha, exclusão e controle, das relações de afetos e desejo, das dinâmicas próprias às lutas políticas, de uma agonística dos corpos e do confronto de suas ações, em suma, de uma história das formas de sociabilidade contemporâneas aos regimes de saber. Tal sincronia subverte "o grande mito Ocidental de que existiria uma antinomia entre saber e poder." Ilusão filosófica que crê que onde há saber "é preciso que ele renuncie ao poder, onde se encontra saber e ciência em sua verdade pura, não pode mais haver poder político" (FOUCAULT, 2001a, p.1438). Antinomia que encontra sua gênese histórica na já referida distinção entre doxa e epistemê, partilha que Foucault retoma não apenas como o momento de despertar da "razão ocidental", mas também, como a invenção de um dos mais antigos sistemas de exclusão próprios a esta cultura. Portanto, a problematização da verdade por parte da genealogia é uma forma de trazer à tona a questão política-moral que se trama e se vela dentro de todo discurso com pretensão de verdade: "Nietzsche começou a demolir, mostrando (...) que por trás de todo saber, por trás de todo conhecimento, o que está em jogo é uma luta 
de poder. O poder político não está ausente do saber, ele é tramado com o saber" (FOUCAULT, 2001a, p.1438).

O resultado de tal tese é que as condições de gênese de um discurso passam para o interior de suas regras e de sua história, mas também redefinem sua natureza como algo eminentemente político. O que não quer dizer que, na esteira de Nietzsche, Foucault faça do saber uma espécie de epifenômeno do campo político-prático-moral que o precede, como se as relações de poder fossem a causa necessária e efetiva de todo e qualquer discurso. O ponto da genealogia é, ao contrário, afirmar que discurso e sociedade são rigorosamente sincrônicos e, consequentemente, se a produção do saber é indissociável de práticas e urgências políticas características de determinada organização social, é também verdade que as formas e práticas sociais podem ser descritas como a versão material e corpórea dos diferentes sistemas de saber. Em uma palavra, não há sobredeterminação exclusiva entre saber e poder, mas sim, uma necessária e intrínseca determinação recíproca. Primeiro ponto de sutura entre saber e poder, Foucault propõem uma imagem semelhante a banda de Möbius: inserção de uma história dos discursos no interior de uma história social e, inversamente, introdução de uma história social no interior de uma história dos discursos ${ }^{10}$. Entre arqueologia e genealogia há uma relação de complementariedade e não de oposição ou contradição.

O que tal relação nos dá a pensar é precisamente a maneira como ela dissolve a contradição corrente entre linguagem e força, razão e opressão, verdade e exclusão ${ }^{11}$. O que está em jogo, sinteticamente, é este dualismo que opõe de forma estrita saber e poder. Recuperando Nietzsche e Détienne, vimos como Foucault pôde partir da ideia de que tal dicotomia não remete a nenhuma verdade originária, mas sim, é o resultado de uma partilha histórica. É apenas com o ocultamento da força persuasiva da linguagem, essa dissociação entre discurso verdadeiro e sofística, entre logos e retórica, que o poder veio opor-se ao saber. De certa forma, a cisão e a distância tornou-se tão acentuada no correr dos séculos que fica difícil compreender em que sentido poderíamos opor saber ao poder, afinal, tudo se passa como se o curso violento do poder apenas fosse possível na ausência da ancoragem do saber. É exatamente contra esses dualismos transformados em senso comum filosófico que Foucault não cansará de nos mostrar como eles apenas perpetuam a violência por outros modos, naturalizando-a através do discurso e transformando-a no nomos próprio às coisas: "Não

\footnotetext{
${ }^{10}$ Sobre isso, devo marcar minha dívida para essa formulação com o estudo de Bento Prado Júnior (2008, p.177).

${ }^{11}$ Sobre a relação entre linguagem e força ver PRADO JR (2008, p.173-186). Texto do qual recupero uma série de desenvolvimentos para pensar as relações de saber-poder em Foucault.
} 
cessamos de passar das palavras de ordem à ordem muda das coisas, como diz Foucault" (DELEUZE e GUATARRI, 2007 p. 28).

Ao se alinhar com a leitura nietzschiana da tradição metafísica e com a história da verdade tal como proposta por Détienne, Foucault pode sustentar uma tese central para a sua genealogia, a saber: "se houve algum esquecimento, trata-se bem menos de um esquecimento do Ser que de uma ocultação da história do poder pela tradição filosófica" (DEFERT, 2011, p. 278). Tese forte que nos auxilia a compreender como a genealogia de Foucault se contrapõe frontalmente a toda temática ontológica do esquecimento-velamento originário do $\operatorname{Ser}^{12}$, ao privilegiar a problemática nietzschiana da relação entre saber e poder.

Ao recuperar esta questão e se contrapor ao seu ocultamento histórico, Foucault coloca-se para fora da interpretação heideggeriana, não apenas quanto a Nietzsche, mas também, e sobretudo, em relação a própria compreensão do sentido de uma história do pensamento escrita como uma história da verdade ${ }^{13}$. A verdade deve ser analisada, doravante, a partir de sua produção e dos efeitos de poder que ela efetiva no mundo e na relação entrehomens e não através de uma hermenêutica que visa desvelar o sentido esquecido, a filigrana de verdade do Ser que escapa no esquecimento da origem. Nesse sentido, a técnica e os esquemas de racionalização criados por determinadas sociedades não serão vistos como uma força que impõe um velamento à forma originária de aparição do fenômeno, ou do ser-no-mundo, mas sim, como jogos de verdade e poder que são condições necessárias e suficientes para que sujeito e objeto possam se constituir e uma relação de determinação, ou conhecimento, possa acontecer:

Para Heidegger é a partir da tékhne ocidental que o conhecimento do objeto selou o esquecimento do Ser. Reviremos a questão e perguntemos a partir de quais tekhnai se formou o sujeito ocidental e que foram abertos os jogos de verdade e do erro, da liberdade e do constrangimento que os caracterizam. (FOUCAULT, 2001b, p. 505).

Tal contraposição à narrativa hermenêutica da verdade é exposta de forma clara e definitiva na aula de 23 de janeiro de 1974 de seu curso O poder psiquiátrico. Curso em que, de forma retrospectiva, Foucault comenta seus esforços - a partir da década de 70 - de

\footnotetext{
${ }^{12}$ Tal tese é defendida, também, pelo citado trabalho de Marcel Détienne. Em uma argumentação já clássica, Détienne mostrou como o vocábulo arcaico Aletheia define o conceito de verdade da Grécia pré-socrática.

${ }^{13}$ Foucault parece se afastar, então, de duas correntes importantes do pensamento filosófico francês: a hermenêutica de Paul Ricoeur e a desconstrução de Jacques Derrida.
} 
recuperação dessa dimensão de poder da verdade que foi historicamente rejeitada e recoberta pela tradição metafísica ocidental:

Há os que têm o costume de fazer a história da verdade em termos de esquecimento do Ser, isto é aqueles que, na medida em que fazem valer o esquecimento como categoria fundamental da história da verdade, se colocam de saída nos privilégios do conhecimento, pois é tão-somente sobre o fundo da relação de conhecimento admitida e posta de uma vez por todas que algo como o esquecimento pode se produzir. (...) O que eu gostaria de fazer, o que procurei fazer nos anos precedentes, foi uma história da verdade a partir de outra série - isto é: procurar privilegiar essa tecnologia, efetivamente rejeitada agora, recoberta, afastada, essa tecnologia verdade-acontecimento, da verdade-ritual, da verdade-relação-de-poder, em face da e contra a verdade-descoberta, a verdade-método, a verdade-relação de conhecimento, a verdade que, por conseguinte, supõe e se situa no interior da relação sujeito-objeto. (FOUCAULT, 2012, p. 305).

Podemos, então, voltar agora para aquele momento de exclusão da sofística que Foucault destacava como um acontecimento chave para sua genealogia. Para ele não basta, apenas, fazer a história da verdade como uma história das variações de suas regras constitutivas. É preciso, também, entender como todo discurso é uma palavra de ordem capaz de produzir e efetivar processos de exclusão, organização e controle do corpo social. E, por isso, uma história da verdade é indissociável de uma história política da verdade, como sempre insistirá Foucault.

Por fim, sublinhe-se como a genealogia não tem dificuldade nenhuma em concordar que uma "proposição verdadeira" derive de um esquema consensual que permite a produção de um saber importante à práxis vital do indivíduo, ou à organização social. Um pouco como no pragmatismo, o que vemos como adequado é aquilo que funciona. Todavia, ao dizermos isso podemos perder o essencial. O fundamental é notar como essa interpretação se inscreve no horizonte polêmico do qual toda genealogia é indissociável. Pois, a principal questão para Foucault é expor a função governamental dos dispositivos de saber-poder - jurídicos, médicos, psicológicos, policiais, estatais, identitários, mercadológicos - precisamente recuperando esse nexo histórico esquecido entre discurso e ordem. Logo, a genealogia não deve ser compreendida rigorosamente como uma redefinição pragmatista da verdade, uma vez que a investigação genealógica é exatamente definida pela recusa da circunscrição da questão do conhecimento e da verdade em termos epistemológicos estritos, abrindo tal problema para a primazia da dimensão política-moral: o que se diz, afinal, por detrás de uma verdade consensual? 
O que está em jogo não é propor outra teoria de justificação da verdade. Mas sim, compreender como não deixamos nunca de passar da ordem do discurso para o discurso da ordem, e vice-versa.

\section{REFERÊNCIAS}

ARISTOTELES. Métaphysique. Paris: Vrin, 1974.

DEFERT, Daniel. Situations du cours. In: Leçons sur la volonté de savoir. Paris: Gallimard, 2011.

DELEUZE, Gilles. Nietzsche et la philosophie, Paris, PUF, 2010.

DeleuZE, Gilles; GUATTARI, Félix. Mille Plateuaux. Paris: Les éditions de minuit, 1980.

DÉTIENNE, Marcel. Les maitres de la verité dans la Grèce archaïque. Paris: Le livre de Poche, 2006.

FOUCAULT, M. Dits et écrits, vol. I. Paris: Gallimard, 2001A.

FOUCAULT, M. Dits et écrits, vol. II. Paris: Gallimard, 2001B.

FOUCAULT, M. As palavras e as coisas. São Paulo: Martins Fontes, 2007.

FOUCAUlT, M. A ordem do discurso. São Paulo: edições Loyola, 1996 (aula inaugural).

FOUCAULT, M. O poder psiquiátrico. São Paulo: Martins Fontes, 2012.

FOUCAULT, M. Leçons sur la volonté de savoir. Paris: Gallimard, 2011C.

LACOUE-LABARTE, P. Le detour. In. Poétique, n.5, Paris, 1975.

LESSA DA FONSECA, Thelma. Nietzsche: Crítica à linguagem como crítica à moral. In: Revista Discurso (25), São Paulo, USP, 1995.

HAN, B. Nietzsche and the "Master of truth", In. Heidegger, Authenticity, and Modernity. MIT, Cambride, 2000

NIETZSCHE, F. Rhetorik. Gesammelte Werke, Vol.5. Munique: Musarion, 1922.

NIETZSCHE, F. Sämtliche Werke. Kritische Studienausgabe. Berlin/München: Walter de Gruyter, 1988.

PRADO JR, B. A retórica de Rousseau, São Paulo, Cosac Naif, 2008.

WOLFF, F. Foucault, l'Ordre du Discours et la Vérité. In. Cahiers philosophiques, septembre 2006. 